\title{
Coping strategies and quality of life in schizophrenia: cross-sectional study
}

\author{
This article was published in the following Dove Press journal: \\ Neuropsychiatric Disease and Treatment \\ 10 December 2015 \\ Number of times this article has been viewed
}

\author{
Michaela Holubova' \\ Jan Prasko ${ }^{1,2}$ \\ Radovan Hruby ${ }^{3}$ \\ Dana Kamaradova ${ }^{1,2}$ \\ Marie Ociskova ${ }^{1,2}$ \\ Klara Latalova ${ }^{1,2}$ \\ Ales Grambal',2 \\ 'Department of Psychiatry, Faculty \\ of Medicine and Dentistry, Palacký \\ University, Olomouc, Czech Republic; \\ ${ }^{2}$ Department of Psychiatry, University \\ Hospital Olomouc, Czech Ministry \\ of Health, Olomouc, Czech Republic; \\ ${ }^{3}$ Psychiatric Outpatient Department, \\ Martin, Slovak Republic
}

\begin{abstract}
Background: The modern psychiatric view of schizophrenia spectrum disorders and their treatment has led to an increasing focus on coping strategies and the quality of life of these patients. In the present study, the authors examined the relationship between demographic data, the severity of symptoms, coping strategies, and the quality of life in psychotic patients. It is important to study the inner experience and striving of these individuals as it has been linked to their well-being and treatment adherence.
\end{abstract}

Methods: Psychiatric outpatients who met International Classification of Diseases, Tenth Revision criteria for a psychotic disorder (schizophrenia, schizoaffective disorder, or delusional disorder) were recruited in the study. Questionnaires measuring the coping strategies (The Stress Coping Style Questionnaire [SVF-78]), the quality of life (Quality of Life Satisfaction and Enjoyment Questionnaire [Q-LES-Q]), and symptom severity (objective and subjective Clinical Global Impression - objCGI; subjCGI) were assessed. The data were analyzed using one-way analysis of variance, Mann-Whitney $U$ test, Pearson and Spearman correlation coefficients, and multiple regression analysis.

Results: A total of 109 psychotic patients were included in the study. The quality of life was significantly related to both the positive and negative coping strategies. The severity of disorder was highly negatively correlated with the quality of life score. The results of multiple stepwise regression analysis using the quality of life as a dependent variable showed that symptom severity (subjCGI, difference between subjCGI, and objCGI), negative coping strategies, positive coping strategies, and the difference between positive and negative coping strategies explain more than half variance.

Conclusion: Our study suggests the importance of utilizing the positive coping strategies in improving the quality of life in patients with psychotic disorders.

Keywords: quality of life, coping strategies, psychotic disorders, schizophrenia, severity of the disorder

\section{Introduction}

The term "coping" describes conscious and unconscious psychic mechanisms, which individuals apply to deal with stress in adaptive ways. ${ }^{1}$ The coping processes include cognitive, emotional, behavioral, and physiological reactions. They are triggered when the acute or chronic stress excess the possibility to solve the situation using skills. ${ }^{2}$ Adaptive coping is understood as flexible and efficient, while maladaptive coping is rigid or socially inappropriate. ${ }^{1}$ The particular types of coping strategies tend to be repeated if they have been efficient in the past. Thus, every individual builds his or her own "coping style". It becomes a part of his or her personality and is understood as a trait. ${ }^{3}$ Individuals use many coping mechanisms to manage and overcome difficult life events, including striving with mental illness.

The concept of coping is important in the current models of psychosis. People with psychotic disorders have been found to use predominately maladaptive coping strategies. ${ }^{4}$ Ritsner et $\mathrm{al}^{5}$ addressed the question whether diverse coping styles
Correspondence: Michaela Holubova Department of Psychiatry, Faculty of Medicine and Dentistry, Palacký University Olomouc, I.P.Pavlova 6, 77520

Olomouc, Czech Republic

Tel +420732536374

Email holubova.mi@seznam.cz 
mediate the relationship between psychopathology, associated distress, and the quality of life among patients with schizophrenia. The quality of life is positively correlated with the task- and avoidance-oriented coping styles and somewhat negatively correlated with emotion-oriented coping. Emotion-oriented coping mediated the connection between the severity of the anxiety/depression symptoms and the quality of life, while avoidance-oriented coping (distraction) influenced the interaction between the quality of life and paranoid symptoms. Coping styles accounted for $25 \%$ of the variance in the subjective quality of life scores compared with $15 \%$ for psychological distress, and only $3 \%$ for clinical factors. Ritsner et $\mathrm{al}^{6}$ studied coping patterns used by hospitalized patients with schizophrenia in comparison with healthy controls. They found that an emotion-oriented coping style and emotional distress were considerably higher in the schizophrenic patients, while the task-oriented coping style, self-efficacy, perceived social support, and satisfaction with the quality of life were lower when compared with the controls. Coping patterns also influence dysphoric mood and emotional distress, self-construct variables, and satisfaction with the quality of life. ${ }^{6}$ Phillips et $\mathrm{al}^{7}$ performed a metaanalysis of 85 studies and concluded that patients with psychosis use most frequently one or two coping strategies. This narrow repertoire of the coping strategies can lead to poorer functioning in life because one or two coping strategies cannot help to deal with a broad range of life stressors.

The coping strategies can also affect the treatment adherence. Denial coping predicted poorer medication adherence in the study of Aldebot and de Mamani. ${ }^{8}$ However, contrary to the expectations, acceptance was not related to medication adherence. In the study of Premkumar et al, ${ }^{9}$ higher pre-therapy coping skills and introspection associated with insight predicted better improvement of symptoms in psychotic patients treated with cognitive-behavioral therapy, but not in the control group of psychotic patients with standard medical care. In the study of Zappia et $a l,{ }^{10}$ the depressive symptoms and the objective quality of life were causative factors to task-oriented coping style, explaining approximately $32 \%$ of the variance. Negative symptoms, the individual quality of life, self-esteem, and insight have been identified as resulted causative factors for the emotionoriented coping strategies, explaining approximately $60 \%$ of the variance. Montemagni et $\mathrm{al}^{11}$ examined the relative contributions of the negative symptomatology, coping, and insight to the quality of life in the outpatients with clinically stabilized schizophrenia. The results suggested that insight and coping-social diversity substantially contributed to the quality of life in patients with stronger negative symptoms.
Kommescher et $\mathrm{al}^{12}$ examined the general coping patterns of individuals at clinically high risk of psychosis and investigated whether pre-therapy coping behavior plays a role in the prediction of responsiveness to early interventions. The outpatients with clinically high risk of psychosis were randomized into two treatment groups: 1) those receiving 1 year of the integrative psychological intervention (including cognitive behavioral therapy); and 2) those with supportive counseling. The participants relied significantly more on the negative than on the positive coping strategies, and within the positive strategies, stress control was the most preferred one. Several pre-therapy coping strategies considerably predicted improvement in the symptomatic outcome in both treatment groups. The predictive value of coping was higher in the group with supportive counseling care. ${ }^{4}$

In the following study, Kommescher et $\mathrm{al}^{12}$ showed that the overall coping styles were similar across the different stages of psychosis. However, clients at clinically high risk of first-episode psychosis used significantly more negative than positive coping styles, likewise patients with multipleepisode psychosis. The first-episode patients with schizophrenia used equally negative as well as positive coping strategies. Across all stages of the disorder, stress control was significantly more preferred in comparison to the other positive coping styles using distraction and devaluation.

The aim of the presented study was to identify, how the coping strategies and the quality of life relate each to the other in the patients with schizophrenia spectrum disorders, and which demographic and clinical factors data influence them.

\section{Methods}

Patients aged between 18 and 60 years diagnosed with schizophrenia spectrum disorders according to the International Classification of Diseases, Tenth Revision ${ }^{13}$ were included in the study. Patients suffering from severe acute symptomatology or with a need for hospitalization and patients with the comorbidity of substance abuse were excluded. The other requirement about patients was sui juris.

\section{Measurements}

\section{The Quality of Life Satisfaction and Enjoyment Questionnaire (Q-LES-Q)}

The questionnaire with 93 items is divided into eight domains. ${ }^{14}$ The included items are physical health, feelings, leisure, social relations, household, job, school/study activities, and an overall score of the quality of life. The patients evaluate their quality of life for the last 7 days. Müllerova validated the Czech version of the method. ${ }^{15}$ 


\section{The Stress Coping Style Questionnaire (SVF-78) ${ }^{16}$}

The questionnaire consists of 78 items divided into 13 scales, each representing a certain way of response to a stressful event: underevaluation, guilt denial, diversion, alternative satisfaction, situation control, reaction control, positive self-instruction, the need for social support, active avoidance, escape tendency, perseveration, resignation, and self-accusation. The levels of the positive and negative strategies are calculated. The Stress Coping Style Questionnaire (SVF-78) was standardized for the Czech cultural background. The internal consistencies of separate scales in the Czech standardization range between 0.77 and 0.94 Cronbach alpha. Average use of coping strategies is declared by the authors between $T$-score of $40-60 .{ }^{16}$ Negative strategies include escape tendency, perseveration, resignation and self-accusation. Positive strategies include underestimation, guilt denial, diversion, compensatory satisfaction, situation control, reaction control, positive self-instruction, and need for social support. Only active avoidance is not recognized in total score (Table 1). ${ }^{17}$

\section{Clinical Global Impression (CGI) ${ }^{18}$}

A global rating of psychopathology based on a 7-point scale ranging from 1 (normal) to 7 (among the most extremely mentally ill patients), based on the symptoms, behaviors, and functioning of the patient over the last 7 days. There exists the objective form performed by the psychologist or psychiatrist (objective Clinical Global Impression, objCGI) and the subjective form in which the patient assesses himself or herself (subjective Clinical Global Impression, subjCGI). The scale is used to evaluate the current severity of psychopathology. ${ }^{18}$

Table I Description of using coping strategies

\begin{tabular}{ll}
\hline Coping strategies & T-score, mean \pm SD \\
\hline Underestimation & $47.77 \pm 12.87$ \\
Guilt denial & $54.35 \pm 12.2$ \\
Diversion & $50.88 \pm 9.88$ \\
Compensatory satisfaction & $55.57 \pm 10.2$ \\
Situation control & $44.95 \pm 11.08$ \\
Reaction control & $47.76 \pm 10.8$ \\
Positive self-instruction & $41.37 \pm 11.95$ \\
Need for social support & $50.98 \pm 11.02$ \\
Active avoidance & $55.76 \pm 8.9$ \\
Escape tendency & $61.82 \pm 9.42$ \\
$\quad$ Rumination/perseveration & $49.9 \pm 12.5$ \\
Resignation & $60.44 \pm 10.95$ \\
Self-accusation & $53.29 \pm 12.61$ \\
Using negative coping & $59.04 \pm 11.24$ \\
Using positive coping & $49.5 \pm 11.8$ \\
\hline
\end{tabular}

Abbreviation: SD, standard deviation.

\section{Demographic questionnaire}

The questionnaire covered elementary data such as sex, age, age at the onset of disorder onset, duration of treatment, marital status, employment status, pension status, education, number of hospitalizations, number of siblings, birth order, heredity of disorder in the family, completeness of the family, and discontinuation of medication in the past (recommended by a psychiatrist or arbitrarily).

\section{Statistical analysis and ethics}

GraphPad Prism version 5.0 and SPSS 17 were used for the statistical analysis. The demographic and clinical characteristics were calculated using the descriptive statistics including frequencies. Shapiro-Wilk $W$ test was used for determining the normal distribution of demographic and clinical data, coping strategies, and quality of life. One-way analysis of variance and Kruskal-Wallis $H$ test served to compare more than two groups of the variable. The differences between two groups were analysed using $t$-tests for independent groups and the Mann-Whitney $U$ test. The categorical data were processed by chi-square or Fisher's exact test. The interactions between variables were calculated using Pearson correlation coefficient or Spearman correlation coefficient. The Tukey's test and Bonferroni's multiple comparison test served for correction in the analysis of variance measurements. The level of significance was determined at $5 \%$.

The ethics committee of University Hospital Olomouc approved the study. The investigation was conducted in agreement with the latest version of the Declaration of Helsinki and the standards of Good Clinical Practice. ${ }^{19}$ All of the patients provided written informed consent before participating in the study.

\section{Results}

\section{Sample description}

Research sample consists of a total of 109 outpatients who were diagnosed with schizophrenia, schizoaffective disorder, polymorphic psychotic disorder, or delusional disorder according to the International Classification of Diseases, Tenth Revision. ${ }^{13}$ There were 41 men and 68 women in the sample. The mean age of respondents was $42.14 \pm 10.42$ years; the minimum age was 24 years, the maximum 67 years. The most frequent diagnosis was schizophrenia $(n=71)$, particularly paranoid schizophrenia $(\mathrm{n}=61)$. The second most frequent disorder was the schizoaffective disorder $(n=31)$; three patients were diagnosed with the acute polymorphic psychotic disorder, and two patients with the persistent delusional disorder. Overall, 103 patients completed all the questionnaires (Table 2). 
Table 2 Description of the sample, demographic and clinical data

\begin{tabular}{|c|c|}
\hline Variable & \\
\hline Age (years) & $41.96 \pm 10.23$ \\
\hline Sex (male:female) & $41: 62$ \\
\hline Age of the disease onset (years) & $26.12 \pm 8.97$ \\
\hline Lifetime duration of treatment & $15.38 \pm 9.52$ \\
\hline Minimum & I \\
\hline Maximum & 45 \\
\hline Number of hospitalizations & $4.13 \pm 3.97$ \\
\hline \multicolumn{2}{|l|}{ Psychiatric heredity } \\
\hline Same disorder & $15(14.6 \%)$ \\
\hline Other disorder & $39(37.9 \%)$ \\
\hline Without & $47(45.6 \%)$ \\
\hline \multicolumn{2}{|l|}{ Education } \\
\hline Elementary & $9(8.7 \%)$ \\
\hline Vocational training & $25(24.3 \%)$ \\
\hline Secondary school & $52(50.5 \%)$ \\
\hline University & $16(15.5 \%)$ \\
\hline \multicolumn{2}{|l|}{ Marital status } \\
\hline Single & $6 \mathrm{I}(59.2 \%)$ \\
\hline Married & $24(23.3 \%)$ \\
\hline Divorced & 15 (14.6\%) \\
\hline Widowed & I (2.9\%) \\
\hline Employment yes/no & $33 / 70$ \\
\hline Retirement & 87 \\
\hline Full invalidity & 60 \\
\hline Partial invalidity & 20 \\
\hline Old-age & 7 \\
\hline From parent family & 66 \\
\hline From incomplete family & 31 \\
\hline Brother/sister, yes/no & $90 / 13$ \\
\hline \multicolumn{2}{|l|}{ Birth order } \\
\hline First-born & 44 \\
\hline Second-born & 36 \\
\hline Third-born & 10 \\
\hline Using psychiatric medication, yes/no & $101 / 2$ \\
\hline Regular use & 94 \\
\hline Regularly, more than prescribed amount & 2 \\
\hline Irregular use & 6 \\
\hline ObjCGI severity & $4.14 \pm 2.75$ \\
\hline SubjCGI severity & $2.75 \pm 1.39$ \\
\hline \multicolumn{2}{|l|}{ Q-LES-Q } \\
\hline Physical health (max score 65) & $4 I .8 I \pm 9.74$ \\
\hline Feelings (max score 70) & $46.33 \pm 10.63$ \\
\hline Work (max score 65) & $27.82 \pm 18.13$ \\
\hline Household (max score 50) & $34.99 \pm 9.04$ \\
\hline School/study (max score 50 ) & $13.47 \pm 8.77$ \\
\hline Leisure (max score 30 ) & $20.15 \pm 5.42$ \\
\hline Social activities (max score 55 ) & $35.69 \pm 9.22$ \\
\hline General (max score 80 ) & $51.49 \pm 12.08$ \\
\hline Total score Q-LES-Q (max score 465 ) & $271.5 \pm 12.47$ \\
\hline Q-LES-Q in percentage & $58.42 \% \pm 12.47 \%$ \\
\hline
\end{tabular}

Note: Data are presented as mean + SD, number (\%), or number.

Abbreviations: max, maximum; ObjCGl, objective Clinical Global Impression; Q-LES-Q, Quality of Life Satisfaction and Enjoyment Questionnaire; SubjCGI, subjective Clinical Global Impression; SD, standard deviation.

\section{Severity of the disorder}

The overall rate of the severity of the disorder assessed by a doctor strongly correlated with subjective evaluation of the patient, but the statistically significant difference was detected between each other. The actual severity of psychopathology assessed by the psychiatrists (objCGI) was $4.14 \pm 0.97$. The subjective assessment of the severity of the disorder (subjCGI) was $2.75 \pm 1.39$. The difference between psychiatrist's and patient's evaluation was $1.67 \pm 1.56$ points. The subjective and objective severity of psychopathology was in moderate positive relation (Spearman $r=0.35 ; P<0.001$ ).

\section{Treatments}

From a total of 103 patients, who completed both questionnaires, 101 of them received prescribed antipsychotic medication from their psychiatrists (98.1\%). Only two of the patients were not taking prescribed drugs at all according to their statement (1.9\%). Ninety-four patients were taking medication regularly in prescribed doses $(91.3 \%)$, and two of them reported overusing of antipsychotic medication $(1.9 \%)$. The remaining six patients, according to their statement, received psychiatric medication irregularly that they sometimes forget to take (5.8\%).

\section{Coping strategies}

One hundred and four patients fulfilled the SVF-78 questionnaire. The patients used more negative than positive strategies (mean $T$-score in negative strategies was $59.04 \pm 11.24$ vs $49.5 \pm 11.8$ in positive strategies; Table 1$)$.

\section{Relation between coping strategies and demographic and clinical variables}

The subjective severity of psychopathology was in moderately negative relation to the strategy underestimation. This strategy further positively correlated with age, marital status and numbers of siblings, and negatively with the objective severity of psychopathology (objCGI). The number of siblings mildly positively correlated with guilt denial, diversion, reaction control, and positive self-instruction. There was a positive correlation between a higher number of siblings and more common use of positive coping strategies. A moderate to strong statistically significant relationship was found between the subjective severity of psychopathology (subjCGI) and both the positive and negative coping strategies. The positive coping strategies (underestimation, diversion, compensatory satisfaction, reaction control, and positive self-instruction) moderately negatively correlated with the subjective severity of psychopathology (subjCGI). Thus, the patients, who evaluate the severity of their disorder as less severe used more positive coping strategies. All the negative coping strategies (escape tendency, perseveration, resignation, and self-accusation) were related positively to 
Table 3 Relations between coping strategies and demographic and clinical variables

\begin{tabular}{lllllllll}
\hline Domain & $\begin{array}{l}\text { Age } \\
\text { (years) }\end{array}$ & Onset & Length & ObjCGI & SubjCGI & $\begin{array}{l}\text { Number of } \\
\text { hospitalizations }\end{array}$ & $\begin{array}{l}\text { Marital } \\
\text { status }\end{array}$ & $\begin{array}{l}\text { Number } \\
\text { of siblings }\end{array}$ \\
\hline Underestimation & $0.205^{*}$ & 0.180 & 0.072 & $-0.198^{*}$ & $-0.389^{* * *}$ & 0.047 & $0.217^{*}$ & $0.290^{* *}$ \\
Guilt denial & 0.075 & 0.046 & 0.040 & -0.078 & -0.153 & 0.074 & 0.080 & $0.209^{*}$ \\
Diversion & -0.078 & -0.101 & 0.004 & -0.021 & $-0.279^{* *}$ & 0.131 & $-0.280^{* *}$ \\
Compensatory satisfaction & -0.112 & $-0.234^{*}$ & 0.166 & -0.030 & $-0.250^{*}$ & 0.181 & -0.092 & 0.056 \\
Situation control & -0.015 & -0.054 & 0.016 & -0.080 & -0.025 & 0.081 & 0.205 \\
Reaction control & 0.054 & -0.021 & 0.020 & -0.102 & $-0.246^{*}$ & 0.077 & 0.029 & 0.023 \\
Positive self-instruction & 0.038 & -0.010 & 0.020 & -0.078 & $-0.390^{* * *}$ & 0.112 & 0.063 & $0.247^{*}$ \\
Need for social support & 0.037 & -0.113 & 0.126 & -0.074 & 0.030 & 0.066 & 0.104 & $0.314^{* *}$ \\
Active avoidance & -0.041 & -0.047 & 0.004 & -0.004 & 0.140 & -0.010 & 0.031 & -0.095 \\
Escape tendency & -0.007 & -0.061 & 0.076 & 0.019 & $0.380^{* * *}$ & 0.035 & -0.079 & -0.008 \\
Perseveration & -0.130 & $-0.253^{* *}$ & 0.087 & 0.143 & $0.298^{* *}$ & 0.026 & -0.040 & -0.007 \\
Resignation & -0.070 & -0.091 & 0.072 & 0.008 & $0.488^{* * *}$ & -0.025 & -0.167 & -0.073 \\
Self-accusation & -0.021 & -0.137 & 0.119 & -0.011 & $0.318^{* *}$ & -0.027 & -0.088 & -0.102 \\
Negative coping & -0.092 & -0.189 & 0.103 & 0.055 & $0.436^{* * *}$ & 0.011 & -0.070 & -0.091 \\
Positive coping & 0.032 & -0.040 & 0.066 & -0.118 & $-0.346^{* *}$ & 0.142 & -0.120 & -0.093 \\
\hline
\end{tabular}

Notes: $* P<0.05 ; * * P<0.01 ; * * * P<0.001$.

Abbreviations: ObjCGI, objective Clinical Global Impression; SubjCGI, subjective Clinical Global Impression.

the subjCGI. Earlier onset of mental illness led to the lower use of compensatory satisfaction and higher perseveration (Table 3).

\section{Quality of life}

One hundred and three patients completed the Q-LES-Q. The average overall score of the quality of life was $58.4 \% \pm 12.47 \%$. The patients reached in average $271.5 \pm 58.03$ points from a maximum of 465 points. The quality of life was the highest in the household domain $(69.98 \% \pm 9.04 \%)$, followed by leisure $(67.17 \% \pm 5.42 \%)$ and feelings domains $(66.19 \pm 10.63)$. Patients achieved the lowest score in the work (42.8 118.13$)$ and school/study (26.94 \pm 8.77$)$ domains. The domains, namely the general quality of life $(64.36 \pm 12.08)$, physical health (67.32 \pm 9.75$)$, and social activities $(64.89 \pm 9.22)$ were approximately equal (Figure 1).

\section{Relation between the quality of life and coping strategies}

The coping strategies were correlated with the overall score of Q-LES-Q score and the various domains of the quality of life. The negative coping strategies were in a moderately negative relation with the overall score of the quality of life, and with all domains except for school/study. Especially, the resignation coping strategy and overall quality of life score were negatively correlated with the highest level of statistical significance. The resignation was strongly negatively associated with the domain feelings, in a moderate relation to the physical health domain and quality of life in general. Positive coping strategies were strongly positively associated with most of the Q-LES-Q domains scores excluding school/ study. The high significant relationship was found between the overall quality of life score and positive self-instructional strategies, and with domains of diversion, reaction control, and underestimation. Positive self-instruction strategies were also strongly associated with several quality of life domains, namely the feelings, physical health, and household domains. Positive strategy domain need for social support had no significant association with the overall score of Q-LES-Q or particular domains of quality of life. Domain school/study was slightly negatively associated only with active avoidance and escape tendencies (Table 4).

\section{Regression analysis}

For the identification of the main factors, which affect the quality of life in patients with schizophrenia spectrum disorders, two stepwise regression analyses were applied. The first model investigated the relationship between the overall score fo the Q-LES-Q as the dependent variable, and negative and positive coping strategies, the objCGI, subjCGI, together with the difference between objCGI and subjCGI as a regressors. The strongest predictors of the overall score of the Q-LES-Q were the subjCGI (beta $=-0.566$ ), positive coping strategies (beta $=0.411$ ), the difference between the objCGI and subjCGI (beta $=-0.377$ ), and the negative coping strategies (beta $=-0.219$ ). The regression model for all of these four variables explains $53.8 \%$ of the overall score variance of the overall score of the quality of life $(F=5.953, P<0.05$; Table 5).

The second model of stepwise regression analysis was used to analyze the overall score of the Q-LES-Q as a dependent 


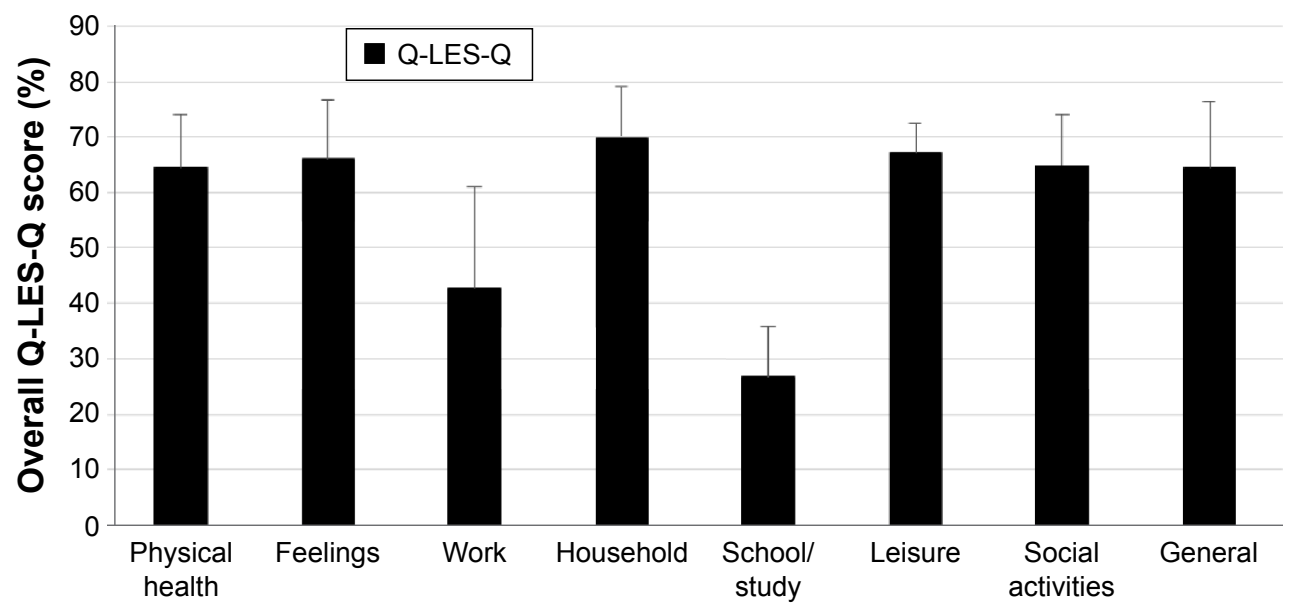

Figure I The domains of the Q-LES-Q and the overall score of Q-LES-Q in percentage. Abbreviation: Q-LES-Q, Quality of Life Satisfaction and Enjoyment Questionnaire.

factor, and objCGI, subjCGI, the difference between objCGI and subjCGI, and all the 13 coping strategies as a regressors. The most significant factors connected to the overall quality of life measured by Q-LES-Q were the positive strategy positive self-instruction ( beta $=0.631$ ), objCGI ( beta $=-0.384$ ), and the difference between objCGI and subjCGI (beta $=0.252$ ). The model using these three variables explained totally $57.6 \%$ of the variance of the overall score of the quality of life ( $F=8.609$, $P<0.01$; Table 6).

\section{Discussion}

The aim of the study was to explore the relationship between the quality of life, the coping strategies, the severity of the disorder, and demographic factors in the patients with schizophrenia spectrum disorders. A closer analysis of these variables showed interesting results. First, quality of life and coping strategies seem to be strongly connected. Using the negative coping strategies was significantly associated with lower quality of life, and using the positive coping strategies with the higher quality of life. These results confirmed the findings of the study of Lim et $\mathrm{al}^{20}$ who found that quality of life was higher in the group with higher active coping (comparable with positive coping) than in the group with passive coping. The active coping was a significant predictor of higher quality of life even after controlling correction for sex, age, Positive and Negative Symptoms Scale (PANSS), and BDI Beck Depression Inventory scores. Also, Rudnick et $\mathrm{al}^{21}$ in their study found out that the level of quality of life was related to the coping strategies focused on emotion, but not to the active, positive coping. The question is if using the coping

Table 4 Correlations between quality of life and coping strategies

\begin{tabular}{|c|c|c|c|c|c|c|c|c|c|}
\hline Coping/domain & $\begin{array}{l}\text { Total } \\
\text { Q-LES-Q }\end{array}$ & $\begin{array}{l}\text { Physical } \\
\text { health }\end{array}$ & Feelings & Work & Household & School & Leisure & $\begin{array}{l}\text { Social } \\
\text { activities }\end{array}$ & General \\
\hline Underestimation & $0.466 * * *$ & $0.318 * *$ & $0.477 * * *$ & $0.269 * *$ & $0.322 * * *$ & 0.098 & $0.332 * *$ & $0.328 * *$ & $0.473 * * *$ \\
\hline Guilt denial & $0.246 *$ & $0.256 * *$ & $0.348 * * *$ & 0.145 & 0.085 & -0.093 & 0.182 & 0.136 & $0.292 * *$ \\
\hline Diversion & $0.486 * * *$ & $0.417^{* * *}$ & $0.444 * * *$ & $0.297^{* *}$ & $0.360 * * *$ & 0.134 & $0.285^{* *}$ & $0.291 * *$ & $0.444 * * *$ \\
\hline Compensatory satisfaction & $0.283^{* *}$ & $0.305^{* *}$ & $0.310 * *$ & 0.147 & $0 .|8|$ & 0.004 & $0.25 I^{*}$ & 0.184 & $0.250 * *$ \\
\hline Situation control & $0.284 * *$ & 0.180 & $0.272 * *$ & 0.141 & $0.322 * *$ & 0.030 & $0.226^{*}$ & $0.260 * *$ & $0.218^{*}$ \\
\hline Reaction control & $0.477 * * *$ & $0.366^{* * *}$ & $0.473^{* * *}$ & $0.247^{*}$ & $0.359 * * *$ & 0.153 & $0.299 * *$ & $0.354 * * *$ & $0.434 * * *$ \\
\hline Positive self-instruction & $0.639 * * *$ & $0.505^{* * *}$ & $0.667 * * *$ & $0.356 * * *$ & $0.503 * * *$ & 0.148 & $0.419 * * *$ & $0.430 * * *$ & $0.563 * * *$ \\
\hline Need for social support & 0.019 & 0.056 & 0.001 & -0.050 & 0.097 & -0.188 & 0.026 & 0.133 & 0.051 \\
\hline Active avoidance & -0.034 & 0.027 & 0.013 & -0.051 & 0.008 & $-0.220 *$ & 0.020 & 0.025 & -0.002 \\
\hline Escape tendency & $-0.274 * *$ & -0.133 & $-0.275^{* *}$ & $-0.236^{*}$ & -0.172 & $-0.228^{*}$ & -0.146 & -0.148 & -0.158 \\
\hline Perseveration & $-0.397^{* * * *}$ & $-0.305^{* *}$ & $-0.454 * * *$ & -0.163 & -0.194 & -0.150 & $-0.369 * * *$ & $-0.266 * *$ & $-0.4 I 5 * * *$ \\
\hline Resignation & $-0.518 * * *$ & $-0.467^{* * * *}$ & $-0.613^{* * *}$ & $-0.244^{*}$ & $-0.377 * * *$ & -0.133 & $-0.353^{* * *}$ & $-0.319 * *$ & $-0.455^{* * *}$ \\
\hline Self-accusation & $-0.319 * *$ & $-0.283 * *$ & $-0.397 * * *$ & $-0.262^{* *}$ & -0.140 & -0.028 & $-0.20 I^{* *}$ & -0.069 & $-0.322 * *$ \\
\hline Negative coping & $-0.468^{* * *}$ & $-0.364 * * *$ & $-0.543^{* * *}$ & $-0.267 * *$ & $-0.275^{* *}$ & -0.153 & $-0.344 * * *$ & $-0.264 * *$ & $-0.434 * * *$ \\
\hline Positive coping & $0.588 * * *$ & $0.48 I * * *$ & $0.615^{* * * *}$ & $0.323 * *$ & $0.438^{* * * *}$ & 0.085 & $0.417 * * *$ & $0.407^{* * * *}$ & $0.547^{* * *}$ \\
\hline
\end{tabular}

Notes: $* P<0.05 ; * * P<0.01 ; * * * P<0.001$.

Abbreviation: Q-LES-Q, Quality of Life Satisfaction and Enjoyment Questionnaire. 
Table 5 First model of stepwise regression analysis of overall score of Q-LES-Q and selected factors

\begin{tabular}{lllll}
\hline Regressors & B & SE & $\boldsymbol{\beta}$ & Significance \\
\hline SubjCGI & -23.637 & 3.927 & -0.566 & $P<0.001$ \\
Positive coping strategies & 7.243 & 1.572 & 0.411 & $P<0.001$ \\
ObjCGI-subjCGI & -15.812 & 5.242 & -0.377 & $P<0.01$ \\
Negative coping strategies & -2.886 & 1.183 & -0.219 & $P<0.05$ \\
\hline
\end{tabular}

Abbreviations: ObjCGl, objective Clinical Global Impression; SE, standard error; SubjCGI, subjective Clinical Global Impression; Q-LES-Q, Quality of Life Satisfaction and Enjoyment Questionnaire.

strategies led to the change of the patient's view on the quality of life, or if the quality of life predicted a higher/lower level of using positive or negative coping or if other factors could influence both. A cross-sectional study is not able to answer the question about causality of these two variables.

Second, up to our results, patients suffering from schizophrenia spectrum disorders use more negative coping strategies than positive ones. Our findings are in agreement recent study of Kommescher et al. ${ }^{12}$ They examined patients with multiple-episode psychosis, first-episode patients, and probands in the risk of psychosis. They found that patients with multiple-episode psychosis used significantly more negative coping styles. On the other hand, the results of the study designed by Lim et $\mathrm{al}^{20}$ were opposite. In this study of schizophrenic patients, there were higher scores of active coping strategies. This difference may be caused by a different concept of the active and passive coping strategies compared to the positive and negative coping strategies used in our study.

Third, the overall score of the quality of life also depends on the degree of severity of the disorder. This finding is in agreement with meta-analysis of Eack and Newhill..$^{22}$ The authors concluded that both positive and negative symptoms of schizophrenia were associated with poor quality of life. A significant relationship was found between the subjective severity of psychopathology and the positive and negative coping strategies. The positive coping strategies (underestimation, diversion, compensatory satisfaction, reaction control, and positive self-instruction) were in the mild-to- moderate

Table 6 Second model of stepwise regression analysis of overall score Q-LES-Q and selected factors

\begin{tabular}{lllll}
\hline Regressors & B & SE & $\beta$ & Significance \\
\hline Positive self-instruction & 7.340 & 3.927 & $0.63 \mathrm{I}$ & $P<0.00 \mathrm{I}$ \\
ObjCGI & -23.818 & 5.242 & 0.384 & $P<0.0 \mathrm{I}$ \\
ObjCGI-subjCGI & 10.579 & $\mathrm{I} .183$ & 0.252 & $P<0.05$ \\
\hline
\end{tabular}

Abbreviations: ObjCGI, objective Clinical Global Impression; Q-LES-Q, Quality of Life Satisfaction and Enjoyment Questionnaire; SE, standard error; SubjCGI, subjective Clinical Global Impression. negative relationship with the subjCGI score. The patients, who evaluated the severity of their psychopathology as less severe, applied more positive coping strategies. All the negative coping strategies (escape tendency, perseveration, resignation, self-accusation) were significantly positively associated with the subjCGI score. A patient, which assesses the severity of his/her psychopathology as more severe, uses more negative coping strategies in the stressful situations.

The present study also pointed to the role of siblings. Having the siblings play a role in the use of positive coping strategies. The higher number of the siblings of patients led to the more frequent use of the positive coping strategies. This may be caused by the higher social support and increased demands for self-assertion, observational learning of problem-solving from siblings or gaining a wider repertoire of possible coping strategies. Furthermore, it was found that the earlier onset of the mental illness led to less use of the compensatory satisfaction and higher use of perseveration. The young age could explain these findings at the start of the disorder, what could diminish the capacity to learn and deal with surrounding demands. Consequently, this diminished capacity could lead to the rumination in the high-demand situations because of a limited repertoire of learned coping strategies.

\section{Limitations}

The main limitation of the study is using the self-report scales and questionnaires. These questionnaires can be significantly affected by the current state of the patient, their willingness to be open in their statements or the cognitive deficits. Also, the severity of illness was assessed only by the overall clinical, rather than by the objective evaluation instruments. Another limitation may be related to selection only stabilized outpatients and those without addiction comorbidity. Another important limitation is that the medication (a type of antipsychotic and dosage) was not monitored. It is impossible to find out if medication could influence the coping or quality of life or the patients.

\section{Conclusion}

The coping patterns and the quality of life may be considered as important sources of knowledge for the patients who struggle with the schizophrenia spectrum disorders and for the as well as mental health professionals. The ability to cope with distress substantially contributes to the quality of life in the patients. The patients who preferred the negative coping strategies displayed the lesser quality of life and conversely, the patients who preferred positive coping strategies had a higher quality of life. The use of the positive and negative coping 
strategies is also associated with the subjective evaluation of the severity of the psychopathology. The strongest factors connected to the overall score of Q-LES-Q is the subjective CGI, the positive coping strategies, the difference between the objCGI and subjCGI, and the negative coping strategies.

These findings proposed the role of some clinical factors as contributing factors to the coping styles. The supportive and psychoeducation strategies and cognitive-behavioral therapy focused to manage psychotic symptoms and to decrease distress could help patients to employ more adaptive coping strategies and improve their quality of life.

\section{Acknowledgments}

We thank the following for their willing cooperation: engineer Miloš Čejka from Hradec Králové, bachelor Václav Holub, MUDr (Master of General Medicine), from Liberec, Jiří Rozkoš, MUDr, from Prostějov, Jan Flídr, MUDr, from Kralupy nad Vltavou, Jana Matějková, MUDR, Simona Papežové, MUDr, and Pavel Tautermann, MUDr, from Prague, Markéta Zemanová, MUDr, from Havlíčkův Brod, Markéta Dobrá, MUDr, from Hrabyně, Zuzana Kozáková, MUDR, from Trutnov (associated with RIAPS [Regionální Institut Akutních Psychosociálních Služeb, Prague]), Tibor Miklóš, MUDR, from Prague, Michaela Zapletalová, MUDr, from Chomutov, Jana Novosadová, MUDr, from Blansko, Jiří Trska, MUDr, from Týn nad Vltavou, Zdeněk Holoubek, MUDr, from Nymburk, Iva Ondráčková, MUDr, from Prague, Andrea Bryčková, MUDr, from Hořice, Jindřiška Masnerová, MUDr, from Beroun, Petr Pastucha, MUDr, from Prostějov, and Hana Lemanová, MUDr, from Brno.

\section{Disclosure}

The authors report no conflicts of interest in this work.

\section{References}

1. Lazarus R. Psychological Stress and the Coping Process. New York (NY): McGraw-Hill; 1996.

2. Cohen S, Kessler RC, Gordon LU. Strategies for measuring stress in studies of psychiatric and physical disorders. In: Cohen S, Kessler RC, Gorden LU, editors. Measuring Stress. A Guide for Health and Social Scientists. Oxford: Oxford University Press; 1995.

3. Lazarus RS. Stress and Emotion. A New Synthesis. New York: Springer; 2006.
4. Kommescher M, Wagner M, Pützfeld V, et al. Coping as a predictor of treatment outcome in people at clinical high risk of psychosis. Early Interv Psychiatry. 2014. Epub $2014 \mathrm{Feb} 25$.

5. Ritsner M, Ben-Avi I, Ponizovsky A, Timinsky I, Bistrov E, Modai I. Quality of life and coping with schizophrenia symptoms. Qual Life Res. 2003;12(1):1-9.

6. Ritsner MS, Gibel A, Ponizovsky AM, Shinkarenko E, Ratner Y, Kurs R. Coping patterns as a valid presentation of the diversity of coping responses in schizophrenia patients. Psychiatry Res. 2006;144(2-3):139-152.

7. Phillips LJ, Francey SM, Edwards J, McMurray N. Strategies used by psychotic individuals to cope with life stress and symptoms of illness: a systematic review. Anxiety Stress Coping. 2009;22(4):371-410.

8. Aldebot S, de Mamani AG. Denial and acceptance coping styles and medication adherence in schizophrenia. J Nerv Ment Dis. 2009; 197(8):580-584.

9. Premkumar P, Peters ER, Fannon D, Anilkumar AP, Kuipers E, Kumari V. Coping styles predict responsiveness to cognitive behaviour therapy in psychosis. Psychiatry Res. 2011;187(3):354-362.

10. Zappia S, Montemagni C, Macrì A, Sandei L, Sigaudo M, Rocca P. Coping styles in schizophrenia: a study of clinical and functional variables as determinants of strategies to cope with stress. Riv Psichiatr. 2012; 47(3):238-245.

11. Montemagni C, Castagna F, Crivelli B, et al. Relative contributions of negative symptoms, insight, and coping strategies to quality of life in stable schizophrenia. Psychiatry Res. 2014;220(1-2):102-111.

12. Kommescher M, Gross S, Pützfeld V, Klosterkötter J, Bechdolf A. Coping and the stages of psychosis: an investigation into the coping styles in people at risk of psychosis, in people with first-episode and multipleepisode psychoses. Early Interv Psychiatry. 2015. Epub 2015 Feb 26.

13. World Health Organization. The ICD-10 Classification of Mental and Behavioural Disorders: Diagnostic Criteria for Research. Geneva: World Health Organization; 1993.

14. Ritsner M, Kurs R, Gibel A, Ratner Y, Endicott J. Validity of an abbreviated Quality of Life Enjoyment and Satisfaction Questionnaire (Q-LES-Q-18) for schizophrenia, schizoaffective, and mood disorder patients. Qual Life Res. 2005;14:1693-1703.

15. Müllerova $H$. Transcultural transmission and validation of the quality life questionnaire Q-LES-Q. Psychiatrie. 2001;5:80-87.

16. Janke W, Erdmannova G. Coping Strategies - SVF 78. Praha: Testcentrum; 2003.

17. Svancara J. Coping Strategies. Prague: Testcentrum; 2003.

18. National Institute of Mental Health. Clinical global impressions (CGI). In: Guy W, editor. ECDEU Assessment Manual for Psychopharmacology. Rockville (MD): National Institute of Mental Health, US Department of Health, Education and Welfare; 1976:217-222.

19. European Medicines Agency EMEA. Reflection Paper on Advice to Applicants/Sponsors/Cross of Bioequivalence Studies; 2002. Available from: http://www.ema.europa.eu/pdfs/human/ich/013595en.pdf. Accessed March 20, 2009.

20. Lim M, Sim M, Chae S, Lee WH, Na J, Kim D. Stress coping strategies and quality of life in patients with schizophrenia. J Korean Neuropsychiatr Assoc. 2015;54(2):181-187.

21. Rudnick A, Martins J. Coping and schizophrenia: a re-analysis. Arch Psychiatr Nurs. 2008;23(1):11-15.

22. Eack SM, Newhill CE. Psychiatric symptoms and quality of life in schizophrenia: a meta-analysis. Schizophr Bull. 2007;33(5):1225-1237.
Neuropsychiatric Disease and Treatment

\section{Publish your work in this journal}

Neuropsychiatric Disease and Treatment is an international, peerreviewed journal of clinical therapeutics and pharmacology focusing on concise rapid reporting of clinical or pre-clinical studies on a range of neuropsychiatric and neurological disorders. This journal is indexed on PubMed Central, the 'PsycINFO' database and CAS,

\section{Dovepress}

and is the official journal of The International Neuropsychiatric Association (INA). The manuscript management system is completely online and includes a very quick and fair peer-review system, which is all easy to use. Visit http://www.dovepress.com/testimonials.php to read real quotes from published authors. 